\title{
Performance of an Active Mass Driver System on a Five Storey Benchmark Model*
}

\author{
Bijan SAMALI**, Mohammed AL-DAWOD*** \\ and Jianchun $\mathrm{LI}^{* * * *}$
}

\begin{abstract}
This paper reports the experimental tests conducted on a 5-storey benchmark model defined by Samali, using an Active Mass Driver (AMD) system, where the control action is achieved by using Fuzzy Logic controller and UTS state-of-the-art shake table facility. The performance of the Fuzzy controller is checked against Hachinohe 1968 and Northridge 1994 earthquake records as input excitation to the benchmark model. The main advantage of the Fuzzy controller is its inherent robustness and ability to handle any non-linear behaviour of the structure. The results of the experimental tests show the ability of the adopted Fuzzy controller to reduce the building responses for the two earthquake records used.
\end{abstract}

Key Words : Structural Control, Active Mass Driver, Fuzzy Controller, Experimental Test, Earthquake Excitation

\section{Introduction}

With the increase in size and flexibility of structures, various ways of protecting them against excessive vibrations caused by severe environmental loads such as wind and earthquake loads have been introduced. One of these methods is the Active Control System such as Active Tuned Mass Damper (ATMD) and Active Mass Driver (AMD) systems in order to reduce the effects of earthquakes and winds ${ }^{(1)}$.

This paper discusses the third stage of applying

* Received 1st November, 2002 (No. 02-5186)

** Professor of Structural Engineering, Centre for Built Infrastructure Research, Faculty of Engineering, University of Technology Sydney, PO Box 123 Broadway Rd, Broadway, NSW, 2007, Australia. E-mail : bijan.samali@uts.edu.au

*** Senior Research \& Development Officer, Centre for Built Infrastructure Research, Faculty of Engineering, University of Technology Sydney, PO Box 123 Broadway Rd, Broadway, NSW, 2007, Australia. E-mail : maldawod@eng.uts.edu.au

**** Senior Lecturer, Centre for Built Infrastructure Research, Faculty of Engineering, University of Technology Sydney, PO Box 123 Broadway Rd, Broadway, NSW, 2007, Australia. E-mail : Jianchun. Li@uts.edu.au an active control scheme to a five storey benchmark model defined by Samali ${ }^{(2)}$. The first stage reported numerical simulation of using an ATMD system on the benchmark model, where the control action is achieved by a Fuzzy Logic Controller (FLC) ${ }^{(3)}$. In the second stage, the active control scheme was applied to the modified benchmark model equipped with an AMD system and the experimental test of the AMD system was reported ${ }^{(4),(5)}$. In this third stage, the performance of the AMD system, where the control action is achieved by using FLC is studied experimentally using University of Technology, Sydney (UTS) state-ofthe-art shake table facility.

Active Mass Driver systems were studied by Spencer ${ }^{(6)}$ on the small-scale three storey, single bay model of 1.58 meters, with a total mass of $227 \mathrm{~kg}$. This study used two earthquake records, $1940 \mathrm{El}$ Centro and 1968 Hachinohe earthquakes.

The main objective of UTS study was to test, experimentally, an active control system with the ability to reduce the response of the buildings under earthquake excitations (e.g. the 1968 Hachinohe and the 1994 Northridge earthquakes). To validate the performance of the proposed system, an AMD system was designed and manufactured at UTS for the large scale model of 3.6 meters. The entire system was tested on the $3 \times 3 \mathrm{~m}, 6$ tonne shake table facility at 
UTS. The table can accommodate any model up to 10 tonnes in weight and can reach accelerations of up to $90 \%$ of gravity in horizontal direction (when fully loaded) at frequencies in the range of 0.1 to $50 \mathrm{~Hz}$.

In the course of the paper, the experimental model and test set up will be described along with the design of the Fuzzy controller and finally the results will be discussed and analysed.

\section{Experimental Structure}

The model used in this study is the benchmark model of 5-storey, 3.6 meters, 2 bays $\times 1$ bay steel frame with plan dimension of $1 \times 1.5 \mathrm{~m}$, designed and manufactured at UTS as shown in Fig. 1. The total mass of the model is $1636.5 \mathrm{~kg}$. An AMD is placed on the top floor. The AMD consisted of a frame fixed to the 5th floor, a trolley with mass on four wheels as a moving mass, and a high pressure hydraulic system to move the trolley and provide the required force to control the building under excitation. For this experiment, a moving mass of $35.1 \mathrm{~kg}$ is fixed inside the trolley and attached to the end of the piston rod.

The hydraulic system consists of a hydraulic pump, accumulator, direct drive servo-valve, actuator, and MVDT (magnetic variable differential transformer) as shown in Fig. 2. The total mass of the structure, including the frame and the AMD is $1671.6 \mathrm{~kg}$. Because hydraulic actuators are inherently open loop unstable, position feedback was employed to stabilise the control actuator. As shown in Fig. 1,

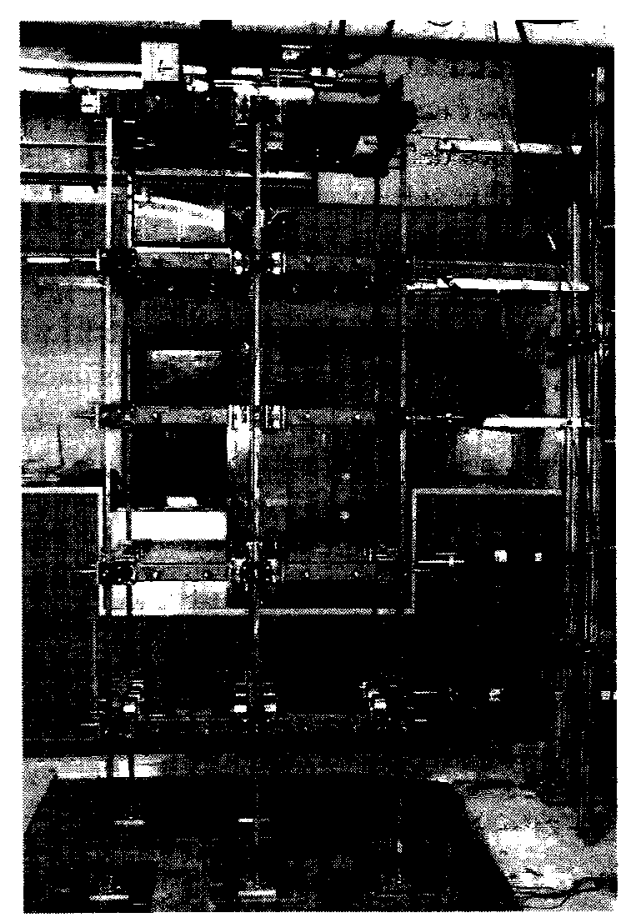

Fig. 1 Experimental setup of the 5-storey benchmark model with AMD system
LVDT's (linear variable differential transformer) were mounted rigidly between each floor and a reaction frame. Also, accelerometers were placed on each floor of the structure, on the AMD and on the base to measure the absolute accelerations. Only, the 5th and 4 th floor displacement measurements were employed for the purpose of control force determination. Experimental system identification tests were conducted on the model to find its dynamic properties.

The five natural frequencies of the model were calculated at $2.95,9.02,15.68,21.26$ and $25.23 \mathrm{~Hz}$, respectively. The corresponding damping ratios were $0.4,0.69,0.63,0.20$ and $0.14 \%$ of critical for the proportional damping matrix. This was achieved by using the shake table and performing swept sine tests, and capturing and analysing resonant frequencies. The five mode shapes associated with the above five frequencies are shown in Fig. 3.

\section{Fuzzy Controller Design}

Fuzzy logic, introduced by Zadeh ${ }^{(7)}$, enables the use of linguistic directions as a basis for control. Generally very robust and capable of handling nonlinear systems, FLC usually require expert knowledge in their construction, a mathematical free model approach. The basic structure of a typical FLC is illustrated in Fig. 4. Various components of this controller are defined as follows:

\section{Fuzzification}

This unit maps the measured inputs, which may be in the form of crisp values, into Fuzzy linguistic values using Fuzzy reasoning mechanism.

\section{Knowledge Base}

This is a collection of the expert control rules (knowledge) needed to achieve the control goal.

\section{Decision Making}

This unit is the Fuzzy reasoning mechanism, which performs various Fuzzy logic operations to infer the control action for a given Fuzzy input.

\section{Defuzzification}

The inferred Fuzzy control action is converted into required crisp control value in this unit.

In this paper, the preliminary design of the controller will use Larsen's minimum product rule, to combine the membership values for each rule, with the

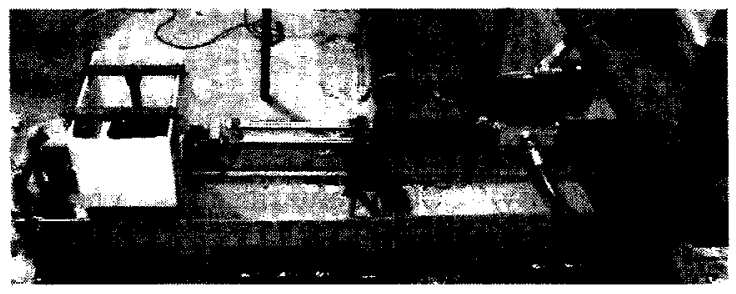

Fig. 2 Active Mass Driver (AMD) system 


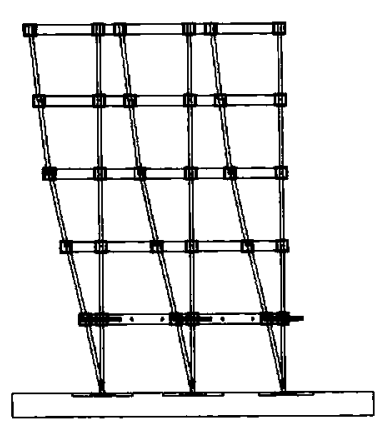

(a) 1st Mode

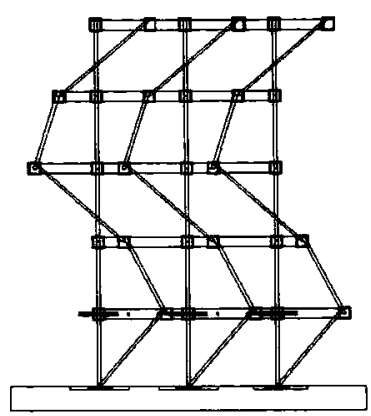

(c) 3rd Mode

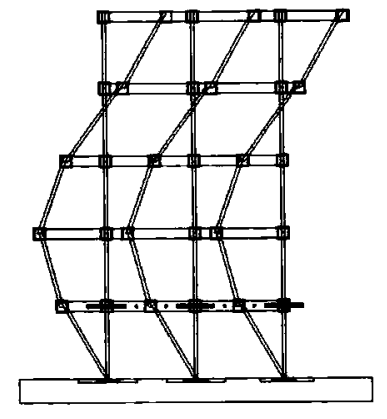

(b) 2nd Mode

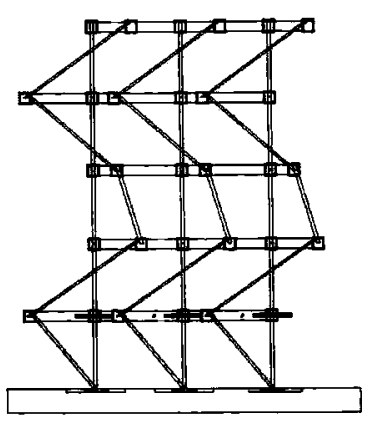

(d) 4th Mode

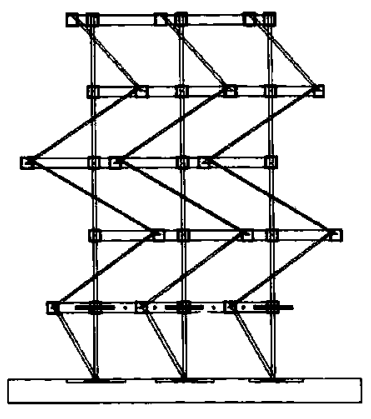

(e) 5th Mode

Fig. 3 Experimental mode shapes for the 5-storey model

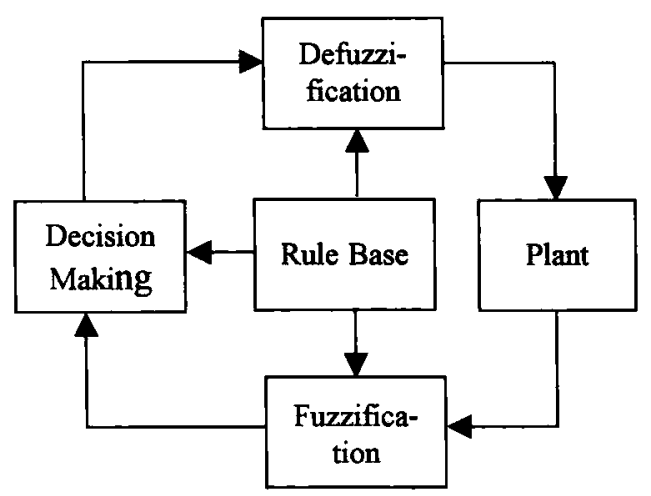

Fig. 4 Basic structure of a FLC

centre of gravity (COG) defuzzification scheme, to obtain the output crisp value.

The controller is designed using two input variables (the displacement of the 5th and 4th floors),
Table 1 Fuzzy variables

\begin{tabular}{|l|l|}
\hline NL & Negative Large \\
NM & Negative Medium \\
NS & Negative Small \\
NVS & Negative Very Small \\
ZR & Zero \\
PVS & Positive Very Small \\
PS & Positive Small \\
PM & Positive Medium \\
PL & Positive Large \\
\hline
\end{tabular}

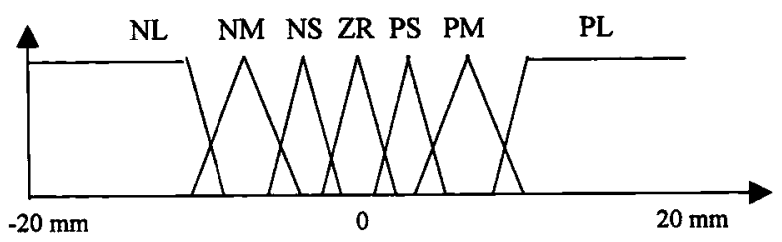

Fig. 5 Membership function for the displacement of 4 th and 5 th floors

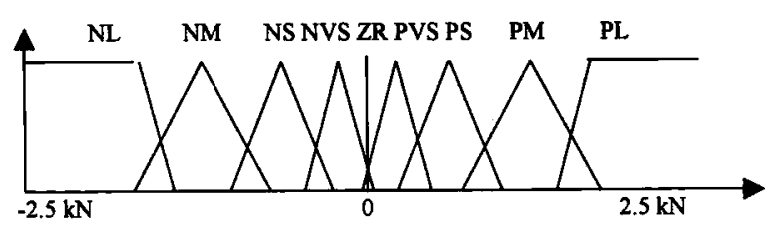

Fig. 6 Membership function for the control force

each one having seven membership functions, and one output variable (the control force) with nine membership functions. The membership functions chosen for the input and output variables are triangular shaped as illustrated in Figs. 5 and 6, respectively. The Fuzzy variables used to define the Fuzzy space are described in Table 1. The self-organising FLC is used to find the final Fuzzy Associative Memory (FAM) and the resulting of 33 rules are shown in Table 2. The aim of using two input variables for the Fuzzy controller is to show the performance of the Fuzzy approach in the control problem. The small number of feedback variables means the use of fewer sensors; thus a simplification of the control system with advantages in terms of reliability and cost.

For the real time control, the Fuzzy controller is implemented into SIMULINK program. This program is compiled in $C$ language through Real Time Workshop toolbox on MATLAB and Real Time Interface (dSpace products) and loaded to the real time data acquisition board (CPU) to run the closed loop control.

\section{Experimental Results}

A $3 \times 3 \mathrm{~m}$ shake table is used to excite the $5^{-}$ 
Table 2 Fuzzy associative memotry (FAM) of the Fuzzy controller

Displacement of $4^{\text {th }}$ floor

\begin{tabular}{|c|c|c|c|c|c|c|c|c|}
\hline $\mathbf{U}$ & NL & NM & NS & ZR & PS & PM & PL \\
\hline & NL & PL & PL & PM & & & & \\
\hline NM & PL & PM & PS & PVS & PVS & & \\
\hline NS & PM & PS & PS & PVS & ZR & ZR & \\
\hline ZR & & PVS & PVS & ZR & NVS & NVS & \\
\hline & PS & & ZR & ZR & NVS & NS & NS & NM \\
\hline PM & & & NVS & NVS & NS & NM & NL \\
\hline PL & & & & & NM & NL & NL \\
\hline
\end{tabular}

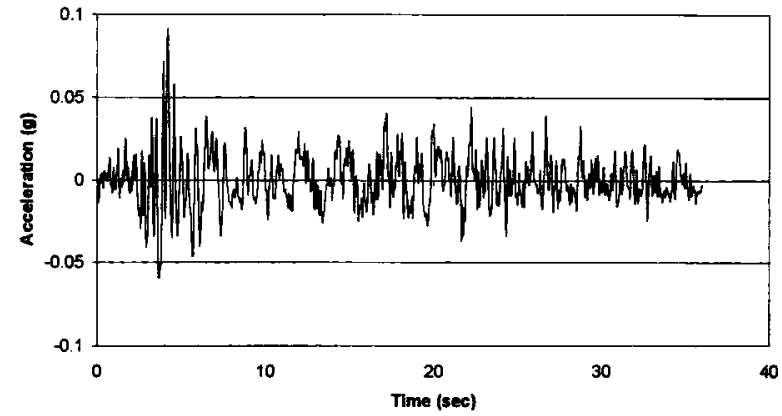

(a) Hachinohe $40 \%$ Intensity

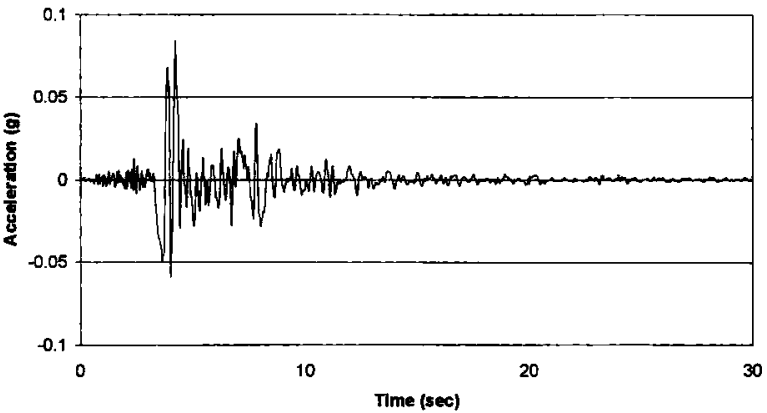

(b) Northridge 10\% Intensity

Fig. 7 Time histories of the earthquakes used (a) Hachinohe 1968; (b) Northridge 1994

storey model using $10 \%$ and $40 \%$ intensities of the 1994 Northridge and the 1968 Hachinohe earthquake records, respectively, as shown in Fig. 7. This is due to limitations of the actuator velocity of $1.6 \mathrm{~m} / \mathrm{sec}$ and the 5-storey model allowable maximum displacement of $25 \mathrm{~mm}$. The benchmark model responses for the controlled and uncontrolled models are measured and a comparison between the controlled and the uncontrolled responses is made to check the performance of the Fuzzy controller.

Table 3 shows the results of the controlled and uncontrolled responses for displacement and acceleration of levels 4 and 5 under Hachinohe earthquake record. Maximum, minimum, peak to peak and RMS responses as well as the peak to peak and RMS
Table 3 Experimental results of the 5-storey model for Hachinohe earthquake

\begin{tabular}{|c|c|c|c|c|c|}
\hline & \multicolumn{2}{|c|}{$\begin{array}{c}\text { Displacement Response } \\
(\mathbf{m m})\end{array}$} & \multicolumn{2}{|c|}{$\begin{array}{l}\text { Acceleration Response } \\
\text { (g) }\end{array}$} \\
\hline & & No control & $\begin{array}{c}\text { With } \\
\text { control }\end{array}$ & No control & $\begin{array}{l}\text { With } \\
\text { control }\end{array}$ \\
\hline \multirow{2}{*}{ Maximum } & L4 & 14.6 & 9.6 & 0.53 & 0.49 \\
\hline & L5 & 16.7 & 11.4 & 0.54 & 0.41 \\
\hline \multirow{2}{*}{ Minimum } & LA & -15.1 & -8.0 & -0.51 & -0.43 \\
\hline & L5 & -17.3 & -9.0 & -0.54 & -0.39 \\
\hline \multirow{2}{*}{$\begin{array}{l}\text { Peak to } \\
\text { peak }\end{array}$} & L4 & 29.7 & 17.6 & 1.04 & 0.92 \\
\hline & L5 & 34.0 & 20.4 & 1.08 & 0.8 \\
\hline \multirow{2}{*}{$\begin{array}{c}\text { Peak } \\
\text { reduction }\end{array}$} & L4 & \multicolumn{2}{|c|}{$40.7 \%$} & \multicolumn{2}{|c|}{$11.5 \%$} \\
\hline & L5 & \multicolumn{2}{|c|}{$40.0 \%$} & \multicolumn{2}{|c|}{$25.9 \%$} \\
\hline \multirow{2}{*}{ RMS } & L4 & 2.96 & 1.79 & 0.100 & 0.067 \\
\hline & L5 & 3.55 & 2.29 & 0.102 & 0.064 \\
\hline \multirow{2}{*}{$\begin{array}{l}\text { RMS } \\
\text { reduction }\end{array}$} & $\mathrm{L} 4$ & \multicolumn{2}{|c|}{$39.5 \%$} & \multicolumn{2}{|c|}{$33.0 \%$} \\
\hline & L5 & \multicolumn{2}{|c|}{$35.5 \%$} & \multicolumn{2}{|c|}{$37.3 \%$} \\
\hline
\end{tabular}

Table 4 Experimental results of the 5-storey model for Northridge earthquake

\begin{tabular}{|c|c|c|c|c|c|}
\hline & & \multicolumn{2}{|c|}{$\begin{array}{c}\text { Displacement Response } \\
(\mathrm{mm})\end{array}$} & \multicolumn{2}{|c|}{$\begin{array}{l}\text { Acceleration Response } \\
\text { (g) }\end{array}$} \\
\hline & & No control & $\begin{array}{c}\text { With } \\
\text { control }\end{array}$ & No control & $\begin{array}{c}\text { With } \\
\text { control }\end{array}$ \\
\hline \multirow{2}{*}{ Maximum } & $\mathrm{LA}$ & 11.2 & 9.3 & 0.37 & 0.32 \\
\hline & L5 & 13.2 & 10.8 & 0.40 & 0.42 \\
\hline \multirow{2}{*}{ Minimum } & L4 & -10.7 & -5.5 & -0.38 & -0.43 \\
\hline & $\mathrm{L} 5$ & -12.6 & -6.6 & -0.39 & -0.39 \\
\hline \multirow{2}{*}{ Peak to peak } & $\mathrm{L} 4$ & 21.9 & 14.8 & 0.75 & 0.75 \\
\hline & L5 & 25.8 & 17.4 & 0.79 & 0.81 \\
\hline \multirow{2}{*}{$\begin{array}{l}\text { Peak } \\
\text { reduction }\end{array}$} & L4 & \multicolumn{2}{|c|}{$32.4 \%$} & \multicolumn{2}{|c|}{$0 \%$} \\
\hline & L5 & \multicolumn{2}{|c|}{$32.6 \%$} & \multicolumn{2}{|c|}{$-2.5 \%$} \\
\hline \multirow{2}{*}{ RMS } & L4 & 2.36 & 1.26 & 0.082 & 0.051 \\
\hline & L5 & 2.77 & 1.49 & 0.085 & 0.048 \\
\hline \multirow{2}{*}{$\begin{array}{c}\text { RMS } \\
\text { reduction }\end{array}$} & $\mathrm{L} 4$ & \multicolumn{2}{|c|}{$46.6 \%$} & \multicolumn{2}{|c|}{$37.8 \%$} \\
\hline & L5 & \multicolumn{2}{|c|}{$46.2 \%$} & \multicolumn{2}{|c|}{$43.5 \%$} \\
\hline
\end{tabular}

reductions are shown in Table 3 . In the same way, Table 4 shows the results of the controlled and uncontrolled responses of levels 4 and 5 under the Northridge earthquake record. The results confirm the ability of the Fuzzy controller to reduce the peak to peak displacement response of levels 4 and 5 by $40.7 \%$ and $40 \%$, and $32.4 \%$ and $32.6 \%$ for Hachniohe and Northridge earthquakes, respectively. And, the reductions in terms of the RMS displacement 

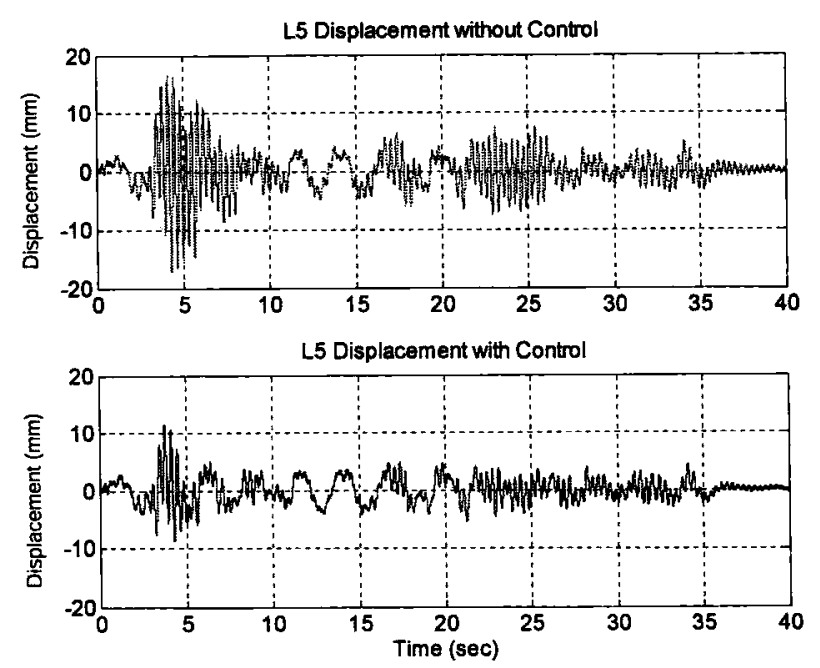

Fig. 8 Time histories of the displacement of level 5 with and without control for Hachinohe earthquake
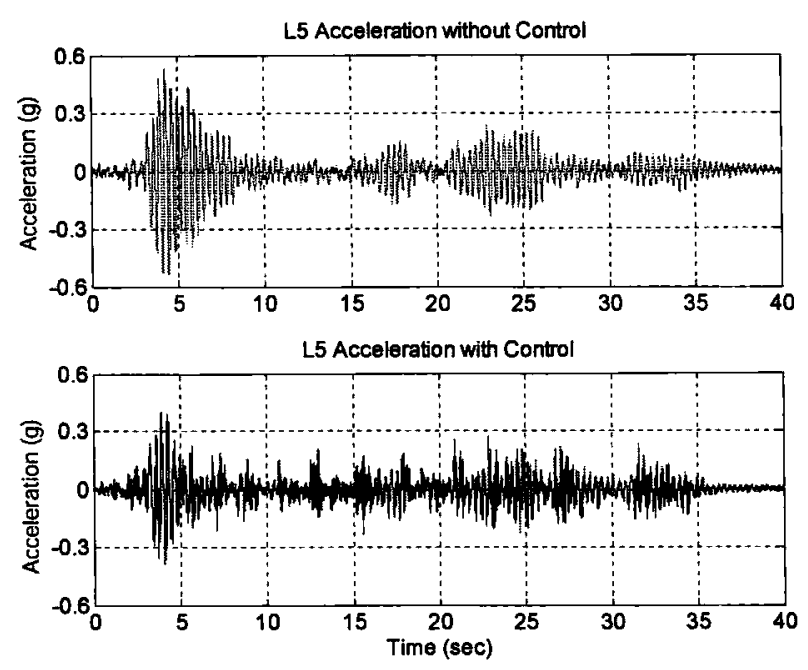

Fig. 9 Time histories of the acceleration of level 5 with and without control for Hachinohe earthquake

responses for levels 4 and 5 are $39.5 \%$ and $35.5 \%$, and $46.6 \%$ and $46.2 \%$ for Hachinohe and Northridge earthquakes, respectively.

The results also show the ability of the Fuzzy controller to reduce the peak to peak acceleration responses for the Hachinohe earthquake by $11.5 \%$ and $25.9 \%$ for levels 4 and 5, respectively, and the RMS acceleration responses by $33 \%$ and $37.3 \%$ for levels 4 and 5 , respectively. For Northridge earthquake, the peak to peak acceleration response is slightly increased for level 5 and is steady for level 4 . Meanwhile, the Fuzzy controller has the ability to reduce the RMS acceleration responses by $37.8 \%$ and $43.5 \%$ for levels 4 and 5 , respectively.

Figure 8 shows the time history responses of level 5 displacements for the controlled and uncontrolled responses under Hachinohe earthquake record. Similarly, Fig. 9 shows the time history responses of level
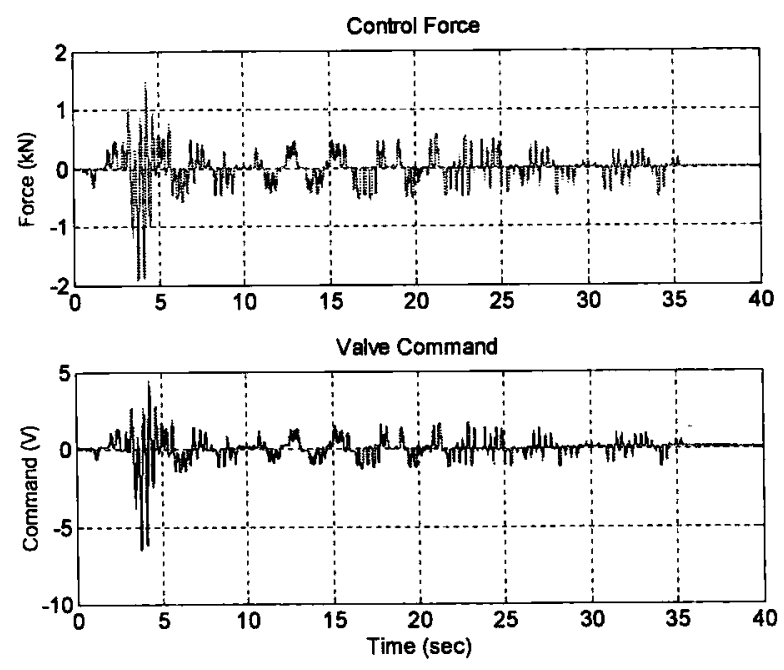

Fig. 10 Time histories of the required control force and valve command for Hachinohe earthquake
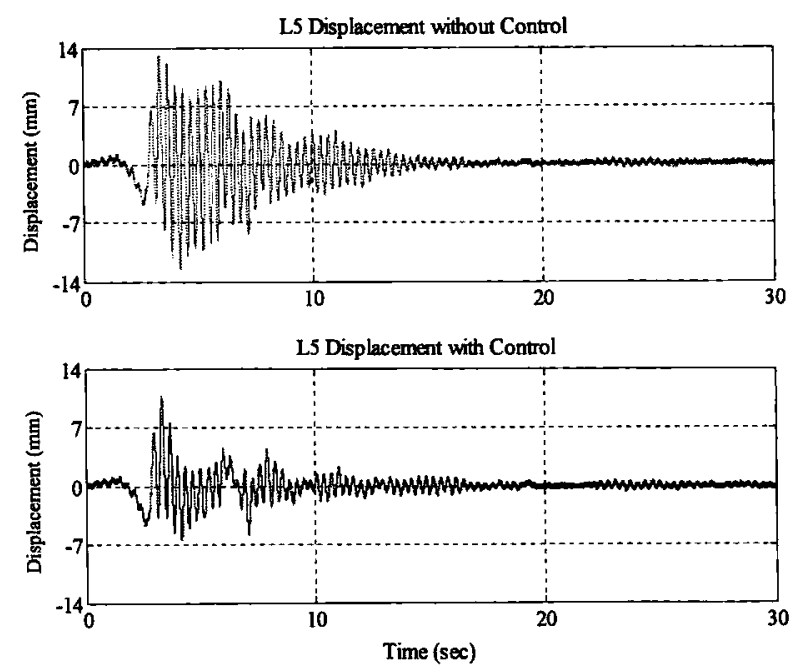

Fig. 11 Time histories of the displacement of level 5 with and without control for Northridge earthquake

5 acceleration. Figure 10 shows the required control force and valve command to achieve the control goal for Hachinohe earthquake. For Northridge earthquake, the time history responses of level 5 displacement and acceleration for the controlled and uncontrolled responses are shown in Figs. 11 and 12, respectively, and Fig. 13 shows the required control force and valve command. The maximum control force required for Hachinohe and Northridge earthquakes are 1.918 and $1.923 \mathrm{kN}$, respectively, and the RMS control force are 0.25 and $0.18 \mathrm{kN}$, respectively. The maximum control forces cited above correspond to control force-building weight ratio of about $12 \%$.

The results of the experimental tests reported in this paper show the potential of using the Fuzzy controller for the active structural control with all the advantages of the Fuzzy controller and will allow 

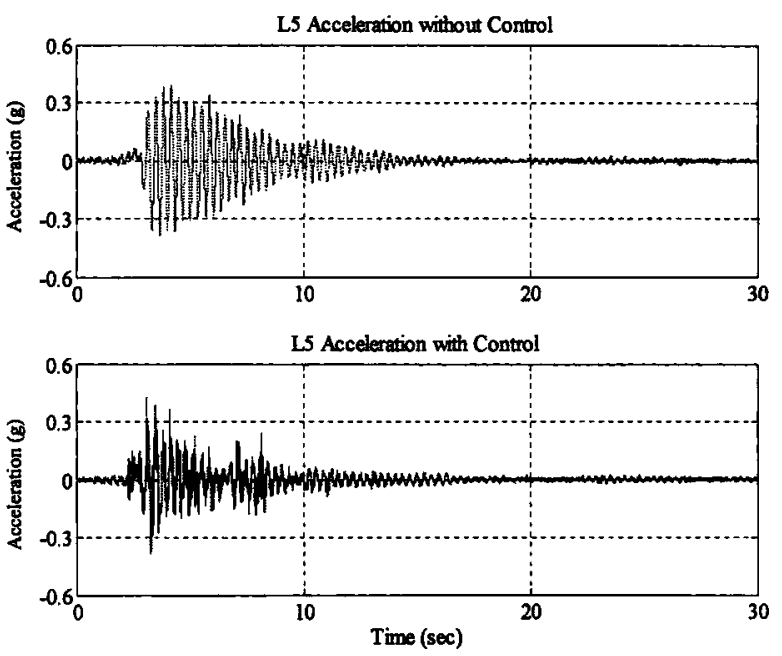

Fig. 12 Time histories of the acceleration of level 5 with and without control for Northridge earthquake
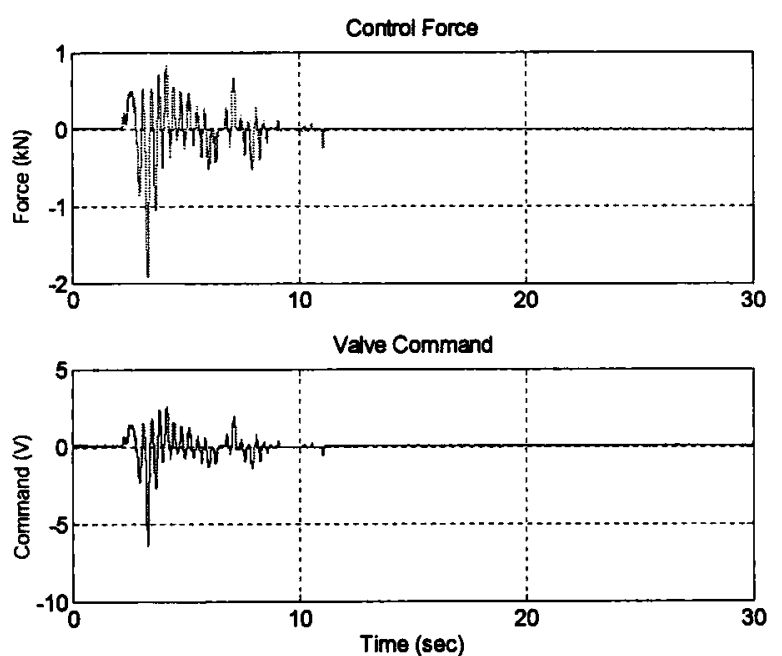

Fig. 13 Time histories of the required control force and valve command for Northridge earthquake

further improvements in the design of the controller to achieve better results.

\section{Conclusion}

The paper reported the experimental tests conducted on UTS 5-storey benchmark model using an AMD system, where the control action is achieved by using FLC, and UTS state-of-the-art shake table facility. The performance of the Fuzzy controller was checked against Hachinohe 1968, and Northridge 1994 earthquake records, as input excitation to the benchmark model with intensities equal to $40 \%$ and $10 \%$ of the original intensities, respectively, due to limitations of the actuator velocity and the maximum allowable 5-storey model displacement.

The Fuzzy controller was implemented into
SIMULINK program. This program was compiled in $C$ language through Real Time Workshop toolbox on MATLAB and Real Time Interface (dSpace products) and loaded to the real time data acquisition board (CPU) to run the closed loop control.

The results show the ability of the Fuzzy controller to reduce the peak displacement responses by up to $40 \%$ and $33 \%$ and the RMS responses by up to $40 \%$ and $47 \%$ for Hachinohe and Northridge earthquakes, respectively. For the acceleration responses, the peak response was reduced by up to $26 \%$ and the RMS by up to $37 \%$ for Hachinohe earthquake. Meanwhile, the peak acceleration responses for Northridge earthquake were not reduced and at times slightly increased, but the RMS responses reduced by up to $47 \%$.

The results of the experimental tests reported in this paper show the potential of using the Fuzzy controller for the active structural control with all the advantages of the Fuzzy controller and will allow further improvements in the design of the controller to achieve better results.

The next stage of this study will investigate necessary modifications to the Fuzzy controller by applying a learning technique.

\section{References}

(1) Leipholz, H., Structural Control, (1987), Martinus Nijhoff, Amsterdam, The Netherland.

(2) Samali, B., System Identification of a Five Storey Benchmark Model Using Modal Analysis, Proc. The Asia-Pacific Vibration Conference '99 Singapore, (1999), pp. 701-706.

(3) Al-Dawod, M., Samali, B., Naghdy, F. and Kwok, K., Active Structural Control of a Five Storey Benchmark Model Using a Fuzzy Controller, Proc. the 5th International Conference on Motion and Vibration Control, Vol. 1 (2000), pp. 151-156.

(4) Samali, B., Al-Dawod, M., Nguyen, H. and Murphy, G., Design and Performance Verification of an Active Mass Damper. Proc. the 5th International Conference on Motion and Vibration Control, Vol. 2 (2000), pp. 837-842.

(5) Samali, B., Al-Dawod, M. and Li, J., Performance of a Five Storey Benchmark Model Using an Active Mass Driver and a Fuzzy Controller, Proc. The 3rd Australian Congress on Applied Mechanics, (2002), pp. 847-652.

(6) Spencer, Jr., B., Dyke, S. and Deoskar, H., Benchmark Problems in Structural Control, Part I : Active Mass Driver System; Part II : Active Tendon System, Earthquake Engineering and Structural Dynamics, Vol. 27, No.11 (1998), pp. 1127-1247.

(7) Zadeh, L., Fuzzy Set, Information and Control, (1965), pp. 338-353. 